Este é um artigo publicado em acesso aberto sob uma licença Creative Commons

https://creativecommons.org/licenses/by-nc/4.0/

\title{
Editorial
}

\section{Universidade em tempos ultraliberais}

\author{
University in ultra-liberal times
}

José Dias Sobrinho ${ }^{1}$

${ }^{1}$ Prof. Titular Aposentado da Universidade Estadual de Campinas

É voz corrente nas universidades e instituições assemelhadas. Ninguém ousa discordar. Propalar a importância da educação superior, atribuir-lhe o papel de farol a iluminar e mostrar os caminhos a seguir, atribuir-lhe funções de motor do desenvolvimento da economia e da sociedade são crenças do senso comum presentes nos meios intelectuais e recorrentemente disseminadas em artigos e pronunciamentos dos gestores. Em princípio, não cabe negar a alta relevância da educação, não tem cabimento simplesmente virar as costas às novas funções que são atribuídas à universidade nestes tempos de incertezas, precariedades e imponderáveis transformações.

Desde sempre a universidade teve obrigações e fins, determinados pelas situações históricas das sociedades. Mas que significa, a rigor, afirmar que à universidade compete impulsionar as transformações da atual sociedade global, esta sociedade que já está sendo guiada pelo e para o mercado? De qual sociedade se fala, quando se fala de mudança da sociedade? Mudar para onde? O mote de mudança está de tal forma incorporado à mentalidade acadêmica, aos meios de comunicação e a amplos setores da sociedade que muito pouco é questionado. Ganhou um selo de verdade e se naturalizou.

Enfatizar a importância da universidade tem como contraponto compreender suas incontornáveis funções e assumir suas responsabilidades. Então, trata-se de pôr no centro das ações e dos discursos as questões fundamentais da formação e do conhecimento. Em semântica reversa, formação tem sido confundida com capacitação de indivíduos para os empregos, o que implica em adaptação e prontidão para responder às novas configurações do trabalho e à criação de novas profissões. Não se trata, então, de formar seres sociais com os fundamentais valores plenamente humanos, e, sim, de fabricar empreendedores, técnicos, trabalhadores treinados para o fortalecimento do mercado feito à medida para e pelas empresas.

Conhecimento não mais significa enriquecimento e elevação do espírito humano e sua capacidade para superar as suas limitações, formar cidadãos conscientes de suas responsabilidades e construir sociedades cultas e justas. Atualmente, o principal critério de valor do conhecimento é sua utilidade para o desenvolvimento do mercado. Por isso, o conhecimento se toma como sinônimo quase perfeito do complexo ciência-tecnologia- 
inovação. Ou ciências básicas e ciências aplicadas, estas ganhando enorme preponderância nas parcerias amplamente estabelecidas entre as universidades e as empresas.

A universidade perdeu, em grande parte, sua histórica missão civilizacional e humanística e, nestes tempos incertos, em acelerada mudança e grave crise civilizacional, progressivamente, vem reforçando e naturalizando seu papel operacional e subserviente aos desígnios da economia globalizada, midiática e de mercado. Expandir as oportunidades de novos tipos de empregos, criar novas áreas de aplicação tecnológica, modernizar aparelhos de comunicação global e imediata, desenvolver patentes e outros semelhantes produtos de inovação, visando a otimização de processos e a ampliação do consumo, acelerar ainda mais as já aceleradas e, muitas vezes, celeradas mudanças, eis as principais tarefas dos centros superiores de formação e ciência.

Aparentemente, em sentido comum, estaria tudo bem com essa visão. Mas não está, pois ela evita ou anula questões fundamentais que, em seu sentido mais forte, se referem aos destinos humanos. Essa concepção de universidade corresponde a qual visão de sociedade e de humanidade? Se a universidade deve liderar as transformações, para qual tipo de mundo são propostas as mudanças? Se o mundo atual se encontra em difíceis encruzilhadas, quais as direções a escolher e quais os meios para superar dilemas e problemas? Como ficam as relações humanas, o reconhecimento do Outro, os projetos de Nação, se o que prevalece é a ideologia da competitividade, da meritocracia e dos atropelamentos para se estar sempre à frente dos demais, ainda que vitimando a ética e a justiça social? Quais as colaborações da universidade operacional, que voltou as costas às preocupações essencialmente humanas, para a construção da humanidade? Ela está centrada na formação integral de seres humanos éticos, cidadãos conscientes de suas responsabilidades na produção de condições mais favoráveis e justas para uma vida solidária e sustentável? Que iniciativas têm tomado as universidades para superar, na medida do possível e tendo em conta seus limites e restrições, as mazelas da ideologia perversa da obsessão geral pelo dinheiro e pelo lucro a qualquer custo? Ou será que as universidades se comprazem em ser os principais instrumentos de sustentação e ponta de lança do ultraliberalismo? Onde ficou perdida sua histórica liderança intelectual na elaboração de grandes sínteses dos eventos e tendências da humanidade? Quais seus contributos para a compreensão dos fenômenos hegemônicos no mundo atual? Para onde nos conduz a aceleração da tecnologia quando cega aos valores essenciais dos homens e das sociedades? Enfim, seus projetos e propósitos realmente cumprem uma missão civilizatória ou abrem brechas para os avanços das novas formas de barbárie?

Muito escassas são as reflexões sobre essas questões. Mais que isso: as análises críticas, as contestações, os questionamentos e as reflexões estão quase totalmente banidas do cotidiano universitário. O trabalho intelectual de mergulho em questões que focam os significados essenciais da vida humana e os caminhos da sociedade estão sendo alijados pela ditadura do produtivismo acadêmico. Nos processos de avaliação correntes, mérito é de quem mais produz e mais publica em periódicos, embora comumente sejam bambos os critérios e exigências de relevância científica e pertinência social.

É bastante cabível o que diz Jorge Bento (2012, p. 69): “A dissensão e o questionamento não são um método de ascensão a patamares de sucesso; são uma necessidade e marca da condição humana e da cidadania - e uma obrigação da função universitária". Cabe acrescentar: obrigação que não é só da universidade, mas também de todos aqueles que têm altas 
responsabilidades na construção da sociedade. Infelizmente, parece já estar largamente instalada a "cultura do desengajamento, da descontinuidade e do esquecimento" (Bauman, p. 2013, p. 36) e amplamente disseminada a aceitação pura e fácil das "verdades autoevidentes" (id., 2013, p. 14). É a inconformidade com relação à apatia social e às perdas de sentido ético da sociedade que faz mais fortes a capacidade e a inevitabilidade da transcendência. Ainda acompanhando Bauman (2013, p. 27): "O Homo Sapiens destaca-se do resto da criação animal por ser indefinido e indeterminado, e, portanto, condenado à transcendência, a desafiar o status quo, a chegar 'acima' e 'além'”.

No fundo, o que verdadeiramente conta e que está em questão é a busca de compreensão, limitadíssima que seja, dos significados mais arraigados da vida humana. Assevera Ladrière (1978, p. 121): “Os elementos verdadeiramente unificadores, os valores mais fundamentais que sustentam, justificam e inspiram a todos os demais, dependem estreitamente das concepções relativas ao destino do homem".

É preciso refletir sobre a grave questão da desigualdade social, sobre as crescentes multidões de miseráveis e dos excluídos da própria pátria, sobre o papel das avançadas e fartamente financiadas tecnologias de guerras, sobre as rupturas do tecido social e o consequente aumento da violência, do ódio, da desídia quanto à sustentação e preservação das bases naturais da vida. O ultraliberalismo tem muito a ver com esse aprofundamento da miserabilidade humana e não tem o direito de se declarar inocente. O que hoje se designa como globalização é, sobretudo, a ampla hegemonia da economia sustentada e agilizada pela onipresença midiática e pela ideologia do lucro ilimitado. Essa economia está se tornando cada vez mais intensa e extensamente ultraliberal. Seu valor central consiste na liberdade do todo poderoso mercado, mais que nos valores profundamente humanos do bem comum, do indivíduo e da vida social.

Ao mesmo tempo que a globalização produz fantásticos avanços científicos e tecnológicos, que afetam a vida de quase todas as pessoas, ela também produz uma perversa globalização das incertezas, dos riscos, da imprevisibilidade do futuro e das inseguranças ante a volatilidade e precariedade destes nossos tempos definidos como "modernidade líquida", segundo feliz formulação de Bauman (2000 e 2001), ou "sociedade de risco", como a chamou Ulrich Beck (2010).

"Sociedade líquida" é o mundo da precariedade. Nada é feito para durar. Tudo está em transição, nada é definitivo. Também os conhecimentos são voláteis, caducam e são postos de lado quando perdem utilidade no mundo dos negócios. Vale a pena refletir sobre algumas das falácias e contradições da globalização apontadas por Boaventura de Sousa Santos (2011, p.53). Diz ele:

"Se para alguns ela continua a ser considerada como o triunfo da racionalidade, da inovação e da liberdade capaz de produzir progresso infinito e abundância ilimitada, para outros ela é anátema já que no seu bojo transporta a miséria, a marginalização e a exclusão da grande maioria da população mundial, enquanto a retórica do progresso e da abundância se torna em realidade apenas para um clube cada vez mais pequeno de privilegiados" 
A economia ultraliberal impediu a realização plena e completa da globalização ao entronizar o empreendedor, o consumidor, o indivíduo competitivo e autorreferente, em lugar do cidadão, do sujeito social responsável pela produção da própria vida e pela construção solidária da sociedade. Faltou a globalização da moral, da justiça social e dos projetos de construção civilizacional. $\mathrm{O}$ que efetivamente se tornou global foi a economia de mercado impulsionada por um sistema informacional-cultural também global. Mas ao mesmo tempo, a hegemonia global da economia de livre mercado e midiática potencializou a globalização da violência, da desigualdade, da competitividade sem freios ético, das guerras e das perdas de referências éticas e valorativas.

A obsessão pela maximização dos lucros e dos benefícios privados instaurada como ideologia central do fundamentalismo do mercado se contrapõe aos valores essenciais do humano, como a solidariedade, a tolerância, o reconhecimento do Outro, a preservação das bases comuns da vida. Para assegurar mais robustamente sua hegemonia, a chamada globalização tratou de promover o empoderamento de organismos políticos, culturais e econômicos de abrangência mundial e mormente alinhados com os interesses dos países e das grandes empresas mais proeminentes: Banco Mundial, FMI, OMC, OCDE, dentre outros. Esses organismos exercem fortes influências sobre a educação, especialmente dos países pobres e emergentes.

Os lugares, agentes e modos de produção de conhecimentos passam por grandes mudanças. Os intelectuais e os cientistas já não gozam da exclusividade que tinham no passado na determinação do campo da formação humana e dos conhecimentos. Embora a universidade ainda seja um lugar privilegiado, socialmente reconhecido, dotado da inteligência de seu conjunto humano e da infraestrutura adequada, a produção e a distribuição dos conhecimentos, atualmente, multiplica e diversifica seus espaços e ambientes, para além das instituições educativas. Os conhecimentos também são produzidos nas grandes empresas multinacionais, na indústria, na agricultura, em institutos de diversas naturezas e finalidades, nas igrejas, nos partidos políticos, nas famílias, nas redes sociais, em toda parte.

Hoje, é muito forte o poder de uma aliança entre cientistas e empresas globais na determinação dos temas mais relevantes e dos critérios de cientificidade e formas de distribuição e apropriação social dos produtos científicos e tecnológicos. Não é majoritariamente a sociedade quem define qual é a ciência necessária para a vida humana mais feliz e axiologicamente mais bem fundada e orientada. $\mathrm{O}$ critério válido para a ciência, em seus aspectos de produção, distribuição e usos sociais, compete mais enfaticamente a reduzidos circuitos internacionais constituídos por uma aliança entre cientistas muito bem remunerados e poderosas empresas globais.

Segundo Dagnino (2003, p. 53), uma teia de relações constituída por grandes empresas, saúde, agricultura e instâncias da defesa, isto é, do setor bélico, produz mecanismos de indução do conteúdo da pesquisa. Afirma ainda que os países que se situam na fronteira científica e tecnológica e no centro do poder mundial são os principais beneficiados com os produtos das pesquisas e com a apropriação das patentes. Eles definem as prioridades e aplicações das investigações. Além disso, também dificultam a concorrência dos países pobres e emergentes.

No plano ideológico, a globalização da economia vem naturalizando a conexão entre os mercados e os sistemas de educação. A economia globalizada serve-se de organizações multilaterais, tais como OCDE, FMI, BM, OMC e outros, como seus tentáculos para disseminar a ideologia e as 
práticas que lhe assegurem a hegemonia global. Assim, determinam os padrões e direções das reformas educacionais, legitimam as políticas públicas setoriais, estabelecem às instituições de educação superior modelos globais de avaliação, pesquisa, ensino e lhes impõem exigências de relações internacionais e configurações com o setor produtivo.

Tudo isso, obviamente, tem a ver com a determinação das novas finalidades da educação superior, agora em conexão direta com a economia globalizada. Guardadas as diferenças e contradições que campeiam nas sociedades, no mundo ultraliberal à universidade se atribui prioridade a funções e papeis alinhados com os interesses das empresas e dos chamados empreendedores, tais como capacitação técnica e profissional, ampliação das condições de empregabilidade, aumento da competitividade, impulso ao avanço da ciência, da tecnologia e da inovação. São relegados aos últimos planos o enriquecimento do patrimônio cultural da nação, a formação de cidadãos, o fortalecimento das relações interpessoais, o desenvolvimento dos objetivos e das práticas sociais da ciência etc.

Já nos anos oitenta do século passado, Castoriadis alertava para a crise da consciência histórica do Ocidente. Para Castoriadis (1983, p.305), "memória viva do passado e projeto de um futuro valorizado desaparecem juntos". Um aspecto perverso desse fenômeno se deve ao abandono da reflexão, do olhar introspectivo e da busca de compreensão crítica do que está ocorrendo no mundo. Bauman (1999, p. 11) afirma que "fazer as perguntas certas constitui, afinal, a diferença entre sina e destino, entre andar à deriva e viajar". E acrescenta: "questionar as premissas supostamente inquestionáveis do nosso modo de vida é provavelmente o serviço mais urgente que devemos prestar aos nossos companheiros humanos e a nós mesmos" (Bauman, 1999, p.11).

Certo é que a tecnociência não deve mover-se solta, livre, isenta de princípios e supostamente esvaziada de valores. É preciso recuperar a humanização da ciência e dos saberes em geral e reinserir a tecnologia no campo dos valores. "A humanização da tecnologia - diz Giddens (1991, p. 169) - é propensa a envolver a crescente introdução de questões morais na relação agora amplamente 'instrumental' entre seres humanos e o meio ambiente criado".

A universidade deve refletir sobre os caminhos e efeitos das inovações tecnológicas e da linguagem instrumentalista tecnoindustrial. É preciso retomar e aprofundar as análises críticas sobre temas que dizem respeito à sobrevivência do mundo e às garantias de futuro, ainda que nisso não haja muita clareza e segura previsibilidade.

Evidentemente, a universidade está muito longe de poder resolver os graves problemas humanos, nem tudo isso é de sua competência, mas é imperdoável não tentar fazer sua parte naquilo que lhe diz respeito e faz parte de suas obrigações e de sua razão de existir. Abdicar da luta é a pior derrota.

As reflexões precedentes conduzem à ideia da urgente necessidade de a práxis científica, particularmente no âmbito universitário, adotar "a crítica de seu autoentendimento histórico" e, "através de alterações em sua autoimagem e em sua configuração política, introduzir freios e contrapesos no 'desgoverno' do avanço científico-tecnológico, atualmente em desabalada e explosiva carreira” (Beck, 2010, p. 273).

Se a universidade quer mesmo mudar o mundo, ainda que só o pouquinho que lhe é possível, é incontornável que ela mesma se engaje em sua própria mudança. Mas só há alguma mudança na universidade, se primeiramente a mudança implicar os atores universitários, 
especialmente os gestores, professores, pesquisadores e demais profissionais da educação. Sem mudança dos indivíduos, não é possível mudar o mundo.

\section{REFERÊNCIAS}

BAUMAN, Zygmunt. Globalização. As consequências humanas. Rio de Janeiro: Zahar. 1999.

BAUMAN, Zygmunt. Modernidade Líquida. Título Original: Liquid Modernity. Tradução: Plínio Dentzien, autorizada da edição inglesa publicada em 2.000 por Polity Press: Oxford, Inglaterra, Rio de Janeiro, Zahar. 2000.

BAUMAN, Zygmunt. Sobre Educação e Juventude. Rio de Janeiro: Zahar , 2013

BECK, Ulrich. Sociedade de risco. Rumo a uma outra modernidade. São Paulo, Editora 34. 2010.

BENTO, Jorge Olímpio. Corrida Contra o Tempo. Posições e Intervenções. Editora da Unicamp, Campinas. 2012.

CASTORIADIS, Cornelius. Socialismo ou barbárie. O conteúdo do socialismo. São Paulo: Brasiliense. 1983.

DAGNINO, Renato. Conferência inaugural. In: KROTSCH, Pedro (org.), Las miradas de La Universidad, III Encuentro Nacional, La Plata, Ediciones Al Margen, 2003.

GIDDENS, Anthony. As Consequências da Modernidade. São Paulo: Editora UNESP. 1991.

LADRIÈRE, J. El reto de la racionalidad. Salamanca: Unesco-Sigueme, 1978.

SANTOS, Boaventura de Sousa. Os processos da globalização. In: SANTOS, Boaventura de Sousa (org.). A Globalização e as Ciências Sociais, 4ªed., São Paulo, Cortez Editora. 2011. 